\title{
ADVANTAGE OF USING AIRCRAFT-TYPE STAGES FOR CREATING "LATLAUNCH" LAUNCH VEHICLE
}

\author{
Sergey Kravchenko ${ }^{1}$, Nikolaj Kuleshov ${ }^{1}$, Vladimir Shestakov ${ }^{1}$, Natalia Panova ${ }^{1}$, Ilmars Blumbergs ${ }^{2}$ \\ ${ }^{1}$ SIA Cryogenic and vacuum systems, Latvia; ${ }^{2}$ Riga Technical University, Latvia \\ sergey@cvsys.eu
}

\begin{abstract}
The demand for launching satellites into the Earth's orbit is constantly growing and becoming marketoriented. In 1985 only 37 out of 253 launched satellites were civilian, mainly owned by government institutions. Now more 2700 satellites operate on the Earth's orbit and over $60 \%$ of them are privately owned. About $70 \%$ of newly launched satellites are light vehicles below $1200 \mathrm{~kg}$, which are launched to LEO and the proportion of this group tends to grow, while the average mass of a spacecraft tends to decrease. The orbit launch cost is the main brake to the commercial exploration of near-Earth space. The cost of launching of a small satellite weighing up to $100 \mathrm{~kg}$ may exceed 100000 EUR per kg. Presently only 9 countries in the world, except ESA member countries, own carriers capable of delivering payload into the Earth's orbit: USA, Russia, Ukraine, Japan, India, PRC, Israel, North Korea and Iran. Attempts to create low-cost carriers are being made by private companies in the USA and Japan: RocketLab (Electron) and SpaceX (various modifications of Falcon); IHI Aerospace (Epsilon, SS-520) and Mitsubishi Heavy Industry N-II. However, in terms of conceptual approaches and main structural solutions, the proposed carriers do not differ fundamentally from those developed in the 1960s-1970s. The Institute of Aeronautics (AERTI) of the Riga Technical University MSTF is developing a LatLaunch aerospace system for launching small satellites into LEO. The project aim is to create a commercial launch system to deliver a payload to LEO at the lowest possible cost per kilogram. The research shows that the declared aim can be achieved through the discard of the first and probably the second stage of the conventional launch vehicle substituting them with reusable aircraft and aircraft-rocket stages. The study analyses the existing launch systems and proposes some new conceptual principles for development of them.
\end{abstract}

Keywords: launch, rocket, spacecraft.

\section{Analysis of existing and prospective launch system technical and economic characteristics}

Approaches to the low-budget system for launching microsatellites into low-earth orbit (LEO) LatLaunch (LatLaunch) concept formulation should base on the idea of achieving competitive advantages. The main one is the low cost of payload per kilogram launching [1].

The obvious way to reduce the launching cost is to create a truly reusable launch system. A reusable launch system (RLS or reusable launch vehicle, RLV) is a launch system that is capable of launching a payload into space more than once, as opposed to disposable ones where each launch vehicle (LV) is launched once and destructs in mission. The cost of RLV is not amortized for one flight, which makes it possible to reduce the launch cost [1].

Many RLS are currently under development. A fully reusable LVs do not currently exist. The ATV Space Shuttle came closest to this edge, but the cost and timing of preparing the used spacecraft for the next flight were comparable to the cost and timing of manufacturing a new LV. Below is a list of major projects underway to create at least partially RLV [2]:

1. Blue Origin New Shepard, USA;

2. SpaceX Falcon Reusable Grasshoppers, USA;

3. Armadillo Aerospace, Stig, USA;

4. Northrop Grumman Hybrid Launch Vehicle, USA;

5. McDonnell Douglas DC-X, USA;

6. XCOR Aerospace EZ-Rocket, USA;

7. ARCA Space Corporation Orizont, USA;

8. Masten Space Systems XA, USA;

9. The Spaceship Company Space Ship 2 Sat Launcher, USA;

10. Rocketplane Global, Inc XP, USA;

11. Scaled Composites Tier 1, USA;

12. Aerojet Rocketdyne RLS, USA;

13. Boeing X37 project, USA;

14. Orbital Sciences Prometeus, USA;

15. Sierra Nevada Corporation Dream Chaser, USA; 
16. RLV-TD ISRO, India;

17. Airbus Defence and Space ADELINE, EU;

18. Skylon Reaction Engines Ltd, UK.

However, the above RLV projects (except for Falcon and partly X37) have not been implemented and are in the development stage, so the main competitors of LatLaunch in the next years will remain the existing disposable LVs, as well as the developing Falcon family.

The main providers of launch services are companies, which purchased exclusive rights to launch an entire LV. The data on the contract value for the launch of a particular spacecraft are confidential, therefore, the cost data available in the public domain contain significant contradictions. When analyzing the materials, it was guided either by close data given repeatedly without cross-references or by public commercial offers [3-15].

If it is necessary to launch a microsatellite without waiting for an accompanying payload, the most attractive is to launch it by Shtil-2 LV. In this case, with an average launch cost of 4-5 million USD, it will be able to put $70 \mathrm{~kg}$ into LEO, and the cost will be 54 100-71 400 USD per $\mathrm{kg}[3 ; 4]$.

All other LVs require a combined load, as they have a load of thousands kg, e.g., Dnepr (3 $700 \mathrm{~kg}$ ), which is usually put to LEO simultaneously about 30-40 satellites. That determines a long waiting period for an associated payload with similar orbit parameters. Dnepr's cost of launching $1 \mathrm{~kg}$ to LEO is 9-12 thousand USD [5; 6].

The Soyuz LV (Russia and ESA) delivers $7020 \mathrm{~kg}$ of a payload to LEO at the price of 2030 thousand USD per kg [8].

China has several commercially available LVs: CZ-2C (Long March 2C) with $3850 \mathrm{~kg}$ LEO load and price 7800 USD per kg [3, 7]; CZ-3BE with $12000 \mathrm{~kg}$ and 5800 USD per kg, CZ-4C with $4200 \mathrm{~kg}$, and 7100 USD per $\mathrm{kg}[3,5]$ and CZ-11 with $530 \mathrm{~kg}$ to LEO and $\mathrm{kg}$ price of $10000 \mathrm{USD}$ [3].

India also serves the global launch market. LV LVM3 can be ordered for 60 million USD and move $8000 \mathrm{~kg}$ to LEO, so its price is 7500 USD per kg. GSLV launches $5000 \mathrm{~kg}$ and has a value of 47 million USD, which means 9400 USD per kg, while PSLV can orbit $3250 \mathrm{~kg}$ for 21 million USD and has a $\mathrm{kg}$ launching price of 6500 USD [3].

ESA is represented by VEGA and Ariane LVs. VEGA can put to LEO $1500 \mathrm{~kg}[7,10]$ or $1963 \mathrm{~kg}$ [3], the mission cost is 42 million [10] to 37 million USD [3]. Kg orbiting price is from 18.8 [3] to 23 [6] - 28 [10] thousand USD. In 2021, it is planned to launch the upgraded Vega-C, delivering to LEO 2300 $\mathrm{kg}$, which will reduce the price of the payload $\mathrm{kg}$ to 15000 USD [11].

Ariane-5 with various upper stages moves $16-22000 \mathrm{~kg}$ to LEO, with the cost of 160-220 million USD [12]. According to [3], the cost of a $20000 \mathrm{~kg}$ mission is 178 million USD with the kg launching price of 8900 USD. In 2022 Ariane- 6 flight is planned. With the same load, its cost should be reduced to 94-117 million USD, which leads to a decrease in the kg launching price to 4 700-5 900 USD [3].

The leading provider of launch services currently is the USA. Active and promising LVs with a cost indicator of less than 20000 USD per kg to LEO transportation, are represented by Antares, which have capability $6600 \mathrm{~kg}$ to LEO and launch price 80-85 million USD (12 900 USD per kg), and Atlas-V, which can orbit a payload of $18814 \mathrm{~kg}$, while the cost of kg launching is 9500 USD [3].

From the operating US LVs, the most attention deserves the Falcon 9, which can launch to LEO $22800 \mathrm{~kg}$ and has 62 million USD price, and the Falcon Heavy, which can launch $63800 \mathrm{~kg}$ for 90 million USD [13], which determines kg to LEO price, respectively, at USD 2720 and 1410.

At the same time, it should be noted that it is of an advertising nature and is not technical documentation that defines the obligations to the flight customer [13]. If check the "Falcon users guide" [14], Section 3.3 "Mass Properties" in Fig. 3-2, it follows that the maximum payload should not exceed $11000 \mathrm{~kg}$ with a maximum height of $2.8 \mathrm{~m}$. Moreover, [14] contains a strict limitation: "Payloads should comply with the mass properties limitations given in Figure 3-2. Payloads can be accommodated as a mission unique service. Payload mass properties should be assessed for all items forward of the payload..., including any mission-unique payload adapters and separation systems. Mass property capabilities may be further constrained by mission-unique payload adapters, dispensers or separation systems", it does not mention any additional load capabilities, including for Falcon Heavy. Then, if someone is guided by the restrictions of [14], then Falcon 9 price for $\mathrm{kg}$ to LEO transport should be 
5636.4 USD, which seems much more realistic. Moreover, if the customer's satellite weighs not 11 tons but less, it will need to use the services of the operator, while the price per kg to LEO transfer will increase from $9750 \mathrm{USD}$ per $\mathrm{kg}$ for $100 \mathrm{~kg}$ satellite to $29500 \mathrm{USD}$ per $\mathrm{kg}$ for $10 \mathrm{~kg}$ CubeSat [15].

Table 1 shows summary data on the main technical and economic indicators of the launch of a payload into LEO by the main LVs.

Table 1

Comparative technical and economic indicators of existing launch systems

\begin{tabular}{|c|c|c|}
\hline Launch vehicle, origin & $\begin{array}{c}\text { Payload mass } \\
\text { delivered to LEO, kg }\end{array}$ & $\begin{array}{c}\text { Payload kg cost to LEO in USD } \\
\text { when paying for the entire LV load }\end{array}$ \\
\hline Shtil 2 (Russia) & 70 & 54100 \\
\hline Sojuz (ESA, Russia) & 7020 & 20000 \\
\hline Dnepr (Ukrain) & 3700 & 10000 \\
\hline CZ-3BE (PRC) & 12000 & 5800 \\
\hline PSLV (India) & 3250 & 6500 \\
\hline VEGA-C (ESA) & 2300 & 15000 \\
\hline Ariane-6 (ESA) & 20000 & 4700 \\
\hline Atlas-V (USA) & 18814 & 9500 \\
\hline Falcon 9 [13] & 22800 & 2720 \\
\hline Falcon 9 [14] & 11000 & 5636 \\
\hline Falcon 9 - 300 kg payload [15] & 300 & 6167 \\
\hline Falcon 9 - 10 kg payload [15] & 10 & 29500 \\
\hline
\end{tabular}

Obviously, when ordering a small load, the price per kilogram orbiting to LEO significantly increases and reaches 20000 USD or more, as a result of which the launch cost approaches the same for non-budget systems.

Thus, when approaching the development of the concept of the LatLaunch LV, it is necessary to be clearly guided by the idea of achieving the main competitive advantage - reducing the cost of launching per $1 \mathrm{~kg}$ of payload into LEO to the level of the competitors' costs and lower when launching loads of hundreds of kilograms into orbit.

It should be guided by the target indicator of realistic Falcon 9 pricing, i.e. 5500 USD per kg, with a payload mass of $1000 \mathrm{~kg}$, then the LatLaunch mission price should not exceed 5.5 million USD, which is 11 times less than the price for the Falcon 9 flight.

A launch system, capable of satisfying such a requirement, must have a completely different technical concept than the existing ones.

\section{Approaches to formation of the LatLaunch concept}

The SciLab-6.1.0 mathematical model was developed to define proper approaches to the LV LatLaunch concept. Mass and power characteristics of budget launchers were analyzed. Based on the manufacturers' data, the characteristic velocity at the end of the operation of the corresponding stage was calculated by the Tsiolkovsky equation:

$$
\Delta V=-v_{e x} \ln \frac{m_{s}}{m_{w f}+m_{s}},
$$

where $\Delta V$ - characteristic velocity, $\mathrm{m} \cdot \mathrm{s}^{-1}$;

$v_{e x}$ - working fluid exhaust velocity, $\mathrm{m} \cdot \mathrm{s}^{-1}$;

$m_{s}$ - rest mass of the spacecraft stage (structure mass) with payload, $\mathrm{kg}$;

$m_{w f}-$ used working fluid mass, $\mathrm{kg}$.

Based on the reference data from the ratio:

$$
T=-v_{e x} G+S\left(P_{e x}-P_{a t m}\right),
$$

where $G$-working fluid mass flow rate, $\mathrm{kg} \cdot \mathrm{s}^{-1}$;

$S$ - stage engines cross-section, $\mathrm{m}^{2}$; 
$P_{e x}-$ working fluid exhaust pressure, $\mathrm{kg} \cdot \mathrm{m}^{-2}$;

$P_{a t m}$ - atmosphere pressure, $\mathrm{kg} \cdot \mathrm{m}^{-2}$, according to the reference data of the stage power plants, the data missing for the solution of equation (1) were determined.

Further, proceeding from the flight characteristics, a numerical method was used to solve the inverse Mieszczerski equation to determine the heading velocity of the stage:

$$
\vec{V}(t)=\frac{1}{m_{w f}+m_{s}} \int \sum_{i=1}^{n}\left\|\vec{F}_{i}\right\| d t-\vec{v}_{e x} \int \frac{1}{m_{w f}+m_{s}} d m_{w f},
$$

where $\vec{V}(t)$ - launcher stage velocity vector, $\mathrm{m} \cdot \mathrm{s}^{-1}$;

$t$ - stage operation time, s;

$\vec{F}_{i}$ - forces, acting on the launcher stage, N.

Also, to determine the flight coordinate along the corresponding stage trajectory (to calculate the flight distance), the solution of the equation of motion for variable mass body was carried out by integrating equation (3) over the operating time of the stage engine:

$$
x(t)=\frac{1}{m_{w f}+m_{s}}\left[\iint \sum_{i=1}^{n}\left\|\vec{F}_{i}\right\| d t d t\right]-\vec{v}_{e x}\left(\iint \frac{1}{m_{w f}+m_{s}} d m_{w f} d t\right),
$$

where $x(t)$-launcher stage movement coordinate along the flight path, $\mathrm{m}$.

Taking into account that in many cases the final speed of the stage is known, when the engine stops, the time of operation of the stage also stops, i.e. stage initial (ignition, start) and shutdown (cutoff) velocity alongside ignition and shutdown time, as well as the corresponding trajectory parameters (for example, flight altitude, stage movement in longitude and latitude), stage characteristics were determined by solving the equation of motion for the flight segment, obtained on the basis of equation (4):

$$
x\left(t_{1}\right)-x\left(t_{0}\right)=\int_{t_{0} t_{0}}^{t_{1} t_{1}} \frac{1}{m_{w f}+m_{s}}\left[\sum_{i=1}^{n}\left\|\vec{F}_{i}\right\|\right] d t d t-\vec{v}_{e x} \int_{0}^{m_{w b} \int_{0}^{t_{1}}} \frac{1}{t_{0}} d m_{w f} d t,
$$

where $x\left(t_{0}\right)$ - launcher stage engine start position on flight path, $\mathrm{m}$;

$x\left(t_{1}\right)$ - launcher stage engine shutdown position on flight path, $\mathrm{m}$;

$t_{0}$ - stage engine start time, s;

$t_{1}$ - stage engine cutoff time, s.

While modelling, the hypotheses about the uniform mass flow rate of the working fluid by the engine of the stage and the use of the entire fuel supply of the stage were used. When preparing the initial data for the calculations, the main sources were used: [14], [16-21] and other sources. The results of modelling the stage characteristics of the main budget launchers are presented in Table 2.

Table 2

Results of the budget launcher characteristics modelling

\begin{tabular}{|l|c|c|c|c|c|c|c|c|}
\hline \multicolumn{1}{|c|}{ Launcher } & Sojuz & Dnepr & CZ-3BE & PSLV & Ariane 6 & Atlas V & $\begin{array}{c}\text { Falcon9 } \\
\mathbf{2 2 . 8 t}\end{array}$ & $\begin{array}{c}\text { Falcon9 } \\
\text { 11t }\end{array}$ \\
\hline LEO max load LV mass, t & 314.45 & 208.9 & 469.33 & 320 & 860 & 587.8 & 549 & 532 \\
\hline Mass factor (load to LV) & 0.0223 & 0.0096 & 0.0245 & 0.0102 & 0.0252 & 0.0320 & 0.0415 & 0.0207 \\
\hline 1 stage mass, t & 177.69 & 161.52 & 180.9 & 89 & 618.4 & 233.5 & 421.3 & 421.3 \\
\hline 1 stage propellant mass, t & 156.24 & 147.9 & 164.4 & 73.2 & 574.4 & 213.2 & 395.7 & 395.7 \\
\hline 1 stage thrust, $\mathrm{kN}$ & 3354 & 4160 & 2961.6 & 4221 & 18600 & 6754 & 7605 & 7605 \\
\hline 1 stage Vex, ${ }^{-1}$ & 2569 & 2873 & 2556.2 & 2569 & 2731 & 2739 & 2765 & 2765 \\
\hline 1 stage burning time, s & 117 & 130 & 140.1 & 70 & 132.8 & 88.3 & 145 & 145 \\
\hline 1 stage separation time, s & 118 & 135 & 141.6 & 75 & 134 & 118 & 148 & 148 \\
\hline 1 stage final $\Delta V, \mathrm{~m} \cdot \mathrm{s}^{-1}$ & 1951 & 3537 & 1102 & 667 & 3010 & 1233 & 3527 & 3769 \\
\hline 1 stage final altitude, $\mathrm{km}$ & 50 & 51 & 56 & 26 & 51 & 44 & 84 & 84 \\
\hline stage/launcher mass ratio & 0.565 & 0.773 & 0.386 & 0.278 & 0.719 & 0.397 & 0.767 & 0.792 \\
\hline
\end{tabular}


Table 2 (continued)

\begin{tabular}{|c|c|c|c|c|c|c|c|c|}
\hline Launcher & Sojuz & Dnepr & CZ-3BE & PSLV & Ariane 6 & Atlas V & $\begin{array}{c}\text { Falcon9 } \\
22.8 t\end{array}$ & $\begin{array}{c}\text { Falcon9 } \\
11 t\end{array}$ \\
\hline stage/launcher $\Delta V$ ratio & 0.203 & 0.372 & 0.115 & 0.069 & 0.313 & 0.130 & 0.433 & 0.362 \\
\hline 2 stage mass, $\mathrm{t}$ & 99.8 & 41.1 & 197.4 & 166.5 & 168.9 & 305.4 & 96.6 & 96.6 \\
\hline 2 stage propellant mass, $t$ & 90.1 & 36.47 & 186.2 & 138.2 & 140 & 284.1 & 92.67 & 92.67 \\
\hline 2 stage thrust, $\mathrm{kN}$ & 792.5 & 775 & 2961.6 & 4800 & 1370 & 3827 & 981 & 981 \\
\hline 2 stage $\operatorname{Vex}, \mathrm{m} \cdot \mathrm{s}^{-1}$ & 2500 & 3128 & 2556 & 2324 & 4246 & 3113 & 3412 & 3412 \\
\hline 2 stage burning time, $s$ & 286 & 190 & 157.5 & 110 & 600 & 252 & 374 & 374 \\
\hline 2 stage separation time, $\mathrm{s}$ & 287.6 & 327 & 159 & 187 & 737 & 257 & 533 & 533 \\
\hline 2 stage final $\Delta V, \mathrm{~m} \cdot \mathrm{s}^{-1}$ & 3226 & 4594 & 2653 & 2119 & 3678 & 5165 & 4626 & 6634 \\
\hline 2 stage final altitude, $\mathrm{km}$ & 170 & 120 & 71 & 67 & 150 & 164 & 168 & 168 \\
\hline stage/launcher mass ratio & 0.317 & 0.197 & 0.421 & 0.520 & 0.196 & 0.520 & 0.176 & 0.182 \\
\hline stage/launcher $\Delta V$ ratio & 0.335 & 0.484 & 0.278 & 0.220 & 0.382 & 0.545 & 0.567 & 0.638 \\
\hline 3 stage mass, $t$ & 27.76 & 3.07 & 55.96 & 48.72 & 43.76 & 23.29 & - & - \\
\hline 3 stage propellant mass, $\mathrm{t}$ & 25.4 & 1.91 & 49.4 & 42 & 31 & 20.83 & - & - \\
\hline 3 stage thrust, $\mathrm{kN}$ & 297.9 & 20.2 & 742 & 799 & 180 & 198.4 & - & - \\
\hline 3 stage $\operatorname{Vex}, \mathrm{m} \cdot \mathrm{s}^{-1}$ & 3520 & 3030 & 2922 & 2873 & 4560 & 4505 & - & - \\
\hline 3 stage burning time, $s$ & 270 & 1000 & 180.4 & 133 & 770 & 772 & - & - \\
\hline 3 stage final $\Delta V, \mathrm{~m} \cdot \mathrm{s}^{-1}$ & 4444 & 1365 & 2357 & 3064 & 2929 & 3075 & - & - \\
\hline 3 stage final altitude, $\mathrm{km}$ & - & - & 169.2 & 218 & - & - & - & - \\
\hline stage/launcher mass ratio & 0.088 & 0.015 & 0.119 & 0.152 & 0.051 & 0.040 & 0.000 & 0.000 \\
\hline stage/launcher $\Delta V$ ratio & 0.462 & 0.144 & 0.247 & 0.318 & 0.305 & 0.325 & 0.000 & 0.000 \\
\hline 4 stage final $\Delta V, \mathrm{~m} \cdot \mathrm{s}^{-1}$ & - & - & 3440 & 2183 & - & - & - & - \\
\hline 5 stage final $\Delta V, \mathrm{~m} \cdot \mathrm{s}^{-1}$ & - & - & 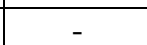 & 1600 & - & - & - & - \\
\hline payload to LEO & 7000 & 2000 & 11500 & 3250 & 21650 & 18814 & 22800 & 11000 \\
\hline total $\Delta V, \mathrm{~m} \cdot \mathrm{s}^{-1}$ & 9621 & 9496 & 9552 & 9634 & 9618 & 9474 & 8154 & 10404 \\
\hline LEO (ISS) need $V, \mathrm{~m} \cdot \mathrm{s}^{-1}$ & 7750 & 7750 & 7750 & 7550 & 7550 & 7550 & 7550 & 7550 \\
\hline$\Delta V$ loss, $\mathrm{m} \cdot \mathrm{s}^{-1}$ & 1871 & 1746 & 1803 & 2084 & 2068 & 1924 & 604 & $2854 *$ \\
\hline
\end{tabular}

* - excess is explained by the possible margin for braking for the 1st stage return.

\section{Results of modeling observation and formulation of the principles of the $\mathrm{LV}$ concept}

The final formulation of the principles for creating the LV LatLunch occurred as a result of the analysis of modeling data based on the concept of the characteristic velocity of the orbital maneuver $\Delta V$. The essence of the $\Delta V$ concept is that for launching a satellite into orbit with a velocity $V_{\text {sat }}$, which is the same for all launch methods, it is set through calculations when determining the satellite target orbit, and in the case of the Earth's orbit it lies between the minimal orbiting velocity of $7.8 \mathrm{~km} \cdot \mathrm{s}^{-1}$ and the escape velocity of $11.2 \mathrm{~km} \cdot \mathrm{s}^{-1}$ :

$$
\Delta V=V_{\text {sat }}+\Delta V_{g}+\Delta V_{d}+\Delta V_{c}+\Delta V_{p} \pm \Delta V_{\text {rot }},
$$

where $\Delta V-$ vector value of the required launcher velocity, $\mathrm{m} \cdot \mathrm{s}^{-1}$;

$V_{\text {sat }}$ - required orbit velocity, $\mathrm{m} \cdot \mathrm{s}^{-1}$;

$\Delta V_{g}$ - gravity velocity losses, $\mathrm{m} \cdot \mathrm{s}^{-1}$;

$\Delta V_{d}$ - aerodynamic resistance velocity loses (drag loses), $\mathrm{m} \cdot \mathrm{s}^{-1}$;

$\Delta V_{c}$ - velocity loses for transformation of the initial speed vector direction to the required orbit velocity vector direction (control velocity loses or steering velocity loses), $\mathrm{m} \cdot \mathrm{s}^{-1}$;

$\Delta V_{p}$ - velocity losses for compensation of the engine thrust reduction in the atmosphere (engine pressure losses, compensating atmospheric pressure), $\mathrm{m} \cdot \mathrm{s}^{-1}$;

$\Delta V_{\text {rot }}$ - projection of the Earth's rotation velocity vector.

Table 2 shows that the total $\Delta V$ loss is about $20 \%$ of the $\Delta V$, which is developed by $L V$ engines. Reducing losses will reduce the required mass of fuel, engine thrust, structure material consumption and the cost of the LV. Let us consider the constituent elements of losses.

The velocity loss component entering into equation (6) - the gravity losses $\Delta V_{g}$ described as: 


$$
\Delta V_{g}=\int_{0}^{t_{\text {fin }}} g \sin \theta d t
$$

where $g$-gravitational acceleration, $\mathrm{m} \cdot \mathrm{s}^{-2}$;

$\theta-$ angle between the launcher trajectory and horizon, degree.

Entering in (7) acceleration of gravity, acting on the LV, mainly depends on the latitude of the launch site and the distance from the Earth's surface. According to [22], the gravitation acceleration can be approximately calculated as:

$$
g=9.780327\left(1+5.3024 \cdot 10^{-3} \sin ^{2}(\varphi)-5.8 \cdot 10^{-6} \sin ^{2}(2 \varphi)\right)-3.086 \cdot 10^{-6} h,
$$

where $\varphi$-geographic latitude, degree;

$h$ - height above sea level, $\mathrm{m}$.

Consequently, the closer to the equator and higher the starting point is the fewer gravitational losses, and with a horizontal start, they are reduced to zero.

Entering into equation (6) losses for the aerodynamic drag $\Delta V_{d}$ are the integral over the flight time of the ratio of the aerodynamic drag force $F_{d}$ to the vehicle mass:

$$
\Delta V_{d}=\int_{t_{0}}^{t_{1}} \frac{F_{d}}{m_{w f}+m_{s}} d t .
$$

The aerodynamic drag force $F_{d}$, from equation (9) is determined as follows:

$$
F_{d}=0.5 \cdot \rho \cdot v^{2} \cdot C_{x} \cdot S,
$$

where $\rho$-air density, $\mathrm{kg} \cdot \mathrm{m}^{-3}$;

$v-\mathrm{LV}$ velocity relative to the flow of air, $\mathrm{m} \cdot \mathrm{s}^{-1}$;

$C_{x}$ - aerodynamic drag coefficient;

$S$ - characteristic area of the $\mathrm{LV}$, its cross-section to the airflow velocity vector, $\mathrm{m}^{2}$.

Air density is significantly dependent on the altitude. According to [23], the standard air density at sea level is $1.2250 \mathrm{~kg} \cdot \mathrm{m}^{-3}$, while at geometric altitudes of 10,25 and $50 \mathrm{~km}$ the density is respectively $0.41351,0.039466$ and $0.001026 \mathrm{~kg} \cdot \mathrm{m}^{-3}$. Therefore, all other things being equal, in accordance with (9) and (10), when the LV is launched from a platform at an altitude of 10,25 and $50 \mathrm{~km}$, the aerodynamic losses will be 3, 30 and 1200 times less, respectively.

The same applies to engine backpressure losses $\Delta V_{p}$, which fall with altitude, while the engine thrust and the specific impulse increase.

The more the control losses $\Delta V_{c}$ decrease, the more the trajectory at the start coincides with the final flight trajectory, and also the smaller disturbance (wind, precipitation, uneven air density) has to be compensated for by the thrust of attitude control vernier engines, that consume the fuel supply and "eat up" the LV mass.

Therefore, the minimum control losses will be at the launch of the carrier in the orbital plane at the maximum altitude and with the minimum angle of attack.

When analyzing the data obtained, it was found that the greatest losses relate to the first stages of the carrier, with $90 \%$ of the losses occurring during the flight to the Kármán line (altitude $<100 \mathrm{~km}$ ).

\section{Conclusions}

The conducted research allows to formulate 3 conceptual principles, guided by which, when designing the LatLaunch carrier, one can achieve a significant reduction in the cost of launch:

1. Reducing the LV mass and cost by reducing the mass of the required fuel by using an aircraft platform for launching and launching the LV from a course coinciding with the plane of the mission's orbit from an altitude of about $10-15 \mathrm{~km}$, from an area as close to the equator as possible (using the linear component of the Earth's rotation velocity);

2. Reducing the LV mass and cost due to the use of atmospheric air as an oxidizer for 1 and possibly 2 stages to overcome the main aerodynamic and gravity drag, and accelerate to a velocity of 2 - 
$3 \mathrm{~km} \cdot \mathrm{s}^{-1}$, the use of wing lift to climb to an altitude of about $45-50 \mathrm{~km}$, and aerodynamic control to high altitudes;

3. The use of fully reusable winged jet-powered supersonic and hypersonic aircraft-type stages and the rocket engine-powered hypersonic aircraft-type stage for further launch of a non-recoverable rocket booster with a payload.

With a decrease in the mass of the propellant required for the flight, this cost is not simply "deducted" from the cost of the mission, but the LV weight decreases, and, consequently, the cost of its structures. The principle of multiple uses of most of the mission equipment allows depreciating its cost in several flights, which will lead to a significant launching price reduction.

\section{Acknowledgments}

The authors are grateful for the support of the Latvian Council of Science, within the framework of which Project No. Lzp-2018/2-0344 "Design and modelling of Aerospace System for Launching picoand nano- Satellites to Low Earth Orbit" the discussed research was performed.

\section{References}

[1] Greason J., Bennett J.C. The economics of space: an industry ready to launch. Los Angeles: Reason Foundation, 2019.97 p.

[2] SpaceFund Reality (SFR) Rating Launch Database. [online] [10.03.2021]. Available at: https://spacefund.com/launch-database/.

[3] Federal Aviation Administration's Office of Commercial Space Transportation. The Annual Compendium of Commercial Space Transportation: 2018. Washington: Federal Aviation Administration, 2018. $255 \mathrm{p}$.

[4] Ecoruspace.me [online] [10.03.2021]. Available at: http://ecoruspace.me/\%D0\%A8\%D1\%82\%D0\%B8\%D0\%BB\%D1\%8C + 2.html.

[5] Roberts T.G. Space Launch to Low Earth Orbit: How Much Does It Cost? Aerospace security. Washington: Center for Strategic and International Studies, 2020 [online]. Available at: https://aerospace.csis.org/data/space-launch-to-low-earth-orbit-how-much-does-it-cost/.

[6] Andreev V.A., Mikhailov V.S., Solovey V.A., Kainov V.V. Cluster Launches of Small Satellites on Dnepr Launch Vehicle. Proceedings of 15-th Annual AIAA/USU Conference on Small Satellites, August 13-16, 2001, Logan, Utah, USA, pp. 1-11.

[7] Massimiani M., Graziani F. IOD/IOV launchers analysis. IODISPLay Horizon-2020 project report, grant agreement ID: 640253, 2015, 42 p. [online] [31.03.2011]. Available at: https://ec.europa.eu/research/participants/documents/downloadPublic?documentIds $=080166 \mathrm{e} 59 \mathrm{c}$ 9623e4\&appId = PPGMS.

[8] Russian launch service provider reveals cost of Soyuz-2.1 rocket launch. TASS Russian News Agency, 03.10.2018. [online] [31.03.2011]. Available at: https://tass.com/science/1024055.

[9] Jones H.W. The Recent Large Reduction in Space Launch Cost. Proceedings of the 48th International Conference on Environmental Systems, July 8-12, 2018, Albuquerque, New Mexico, USA, ICES-2018-81, p.p. 1-10.

[10] De Selding P.B. Vega Expected to be Price-competitive with Russian Rockets. Spacenews, 23.01.2012. [online] [10.03.2021]. Available at: https://spacenews.com/vega-expected-be-pricecompetitive-russian-rockets/.

[11] Vega-C features. ESA, 31.05.2019. [online] [10.03.2021]. Available at: https://www.esa.int/Enabling_Support/Space_Transportation/Launch_vehicles/Vega-C.

[12] Forrester C. SpaceX reduces launch costs. Advanced Television Ltd, 8.10.2019. [online] [10.03.2021]. Available at: https://advanced-television.com/2019/10/08/spacex-reduces-launchcosts/.

[13] SpaceX. Capabilities \& services. [online] [10.03.2021]. Available at: https://www.spacex.com/media/Capabilities\&Services.pdf.

[14] SpaceX. Falcon users guide. August 2020. [online] [10.03.2021]. Available at: https://www.spacex.com/media/Falcon_Users_Guide_082020.pdf.

[15] Spaceflight. Pricing information. [online] [10.03.2021]. Available at: https://spaceflight.com/pricing/. 
[16] Arianespace. Soyuz at the Guiana Space Centre. User's Manual. Issue 2 - Revision 0. Cedex: Arianespace, 2012. $244 \mathrm{p}$.

[17] International Space Company Kosmotras. Space Launch System Dnepr User's Guide. Moscow: Kosmotrans, 2001. $76 \mathrm{p}$.

[18] China Aerospace Science and Technology Corporation. Long March 3A (LM-3A) Series Launch Vehicle User's Manual. Issue 2011. Beijing: CAASC, 2011. 254 p.

[19] Indian Space Research Organisation. Polar Satellite Launch Vehicle (PSLV). Bangalore: ISRO, 2017. [online] [10.03.2021]. Available at: https://www.isro.gov.in/launchers/pslv.

[20] Arianespace. Ariane 6 user's manual. Issue 1-Revision 0. Cedex: Arianespace, 2018. 173 p.

[21] United Launch Alliance. Atlas V launch services user's guide. Revision 11. Centennial: United Launch Alliance, 2010. 420 p.

[22] Geodetic Reference System, adopted by XVII General Assembly of the IUGG, Canberra, 1980.

[23] U.S. Standard Atmosphere, 1976. Washington: U.S. Government Printing Office, 1976. 243 p. 